Editorial

\title{
European Guidelines for Urology Sexual and Reproductive Health 2020. Why is it Worth it to read it?
}

\section{Guías Europeas en salud sexual y reproductiva 2020. ¿Por qué vale la pena leerlas?}

\author{
Alejandro Carvajal ${ }^{1}$ Juan Ignacio Martínez-Salamanca ${ }^{2}$ \\ ${ }^{1}$ Departamento de Urologìa, Universidad CES, Medellìn, Colombia \\ 2 Lyx Instituto de Urologia, Universidad Francisco de Vitoria, Hospital \\ Universitario Puerta de Hierro, Madrid, España \\ Urol Colomb 2020;29:69-70.
}

The European urology guidelines have been written since 1996. In 2000, experts included sections on ejaculation disorders and erectile dysfunction. ${ }^{1}$ Since then, each year, they are updated with the competition of specialists from different continents. In 2014, authors introduced the term priapism, ${ }^{2}$ and they maintained it until 2018. That same year the guidelines were modified based on the new online educational courses designed by the EAU expert panels and a group of young urologists. For the year 2020 and with the consultation of more than 250 experts from 72 countries, the guidelines gathered in a single chapter (Sexual and Reproductive Health) with extensive content that is worth consulting.

Among the novelties, there is a complete change in the chapter regarding the hypogonadism. The use of testosterone replacement is recommended in patients with abnormal values and with erectile dysfunction supported by the Sexual Function trial of testosterone trials since experts previously recommended first use of PDE5 inhibitors. Another issue is the explanation of the effects of hormonal replacement on organs such as prostate and breast as well as how this affects the cardiovascular system.

The treatment approach for managing erectile dysfunction changed. After an initial evaluation with a detailed medical history, authors suggest identifying the expectations of the patients to make a joint decision and also offer treatment of physical and psychosexual aspects. Psychosexual therapy continues to be an essential tool in the treatment, better if there is a good follow-up. In the case of choosing a behavioral and cognitive therapy (CBT), they suggest considering its combination with pharmacotherapy. Subsequently, there are different treatment alternatives such as intracavernous injections, vacuum devices, oral therapy with a PDE5 inhibitor and topical and intraurethral treatments. All considered as first line of treat-

Address for correspondence Alejandro Carvajal, MD, FECSM, Departamento de Urologìa, Universidad CES, Medellìn, Colombia

(e-mail: ac@sexualidadyfertilidad.com). ments. Shock wave intervention ${ }^{3}$ is also recommended as an option in vasculogenic patients with prior informed consent and after previous treatments as the first line of treatment.

The management of Peyronie's disease was extensively reviewed, considering the publication of many of the genes involved in its pathophysiology and its relationship with Dupuytren's disease. ${ }^{4}$ Only oral non-steroidal anti-inflammatory drugs (NSAIDs) and phosphodiesterase inhibitors are considered as oral therapy and other options previously considered withdrawn. Despite the recent withdrawal from the European market of collagenase of clostridium histolyticum by its marketing company, the results of the most significant studies regarding the improvement of penile curvature based on the IMPRESS study (Investigation for Maximal Peyronie's reduction efficacy and safety studies) were published. ${ }^{5}$ The curvature improvement is $34 \%$ versus $18.2 \%$ in the placebo group. Patients with curvatures between 30 and 60 degrees, IIEF greater than 17, without calcified plaques and a longer duration of the disease, were those who benefited the most from the treatment. A new shorter protocol for administration of collagenase was mentioned. ${ }^{6}$ The use of interferon- $a-2 b$ is included as a recommended treatment in the stable phase of the disease due to a $20 \%$ reduction in curvature in a recent study, and the few side effects it can cause. Experts reviewed other types of treatments, such as traction therapy. Although they mentioned them as a possible safe and effective option, current studies do not support their use as monotherapy. The vacuum devices are also mentioned as a possible mechanism of mechanical straightening of the curvature but with only one study that recommends it as monotherapy.

Regarding surgical management, they better described the surgical technique of penile shortening techniques, reporting penile rectification rates greater than $85 \%$. They mentioned

Copyright $\odot$ 2020, Sociedad Colombiana License terms de Urología. Publicado por Thieme Revinter Publicações Ltda., Rio de Janeiro, Brazil. Todos los derechos reservados.

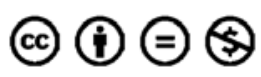

DOI https://doi.org/

ISSN 0120-789X. e ISSN 2027-0119. 
techniques with geometric principles as an option and tunic shortening and lengthening procedures, taking into account the latter types of grafts used and the results obtained.

In the chapter on ejaculation disorders, they completely described the pathophysiology and possible causes of hematospermia. In addition to mentioning the types of studies that must be performed, they also reported how to investigate the cause in the initial presentation and recurrent cases.

In male infertility, experts presented a text with many modifications (the first published in 2001, updated several years and in 2017 expanded to cover areas not previously mentioned). The diagnostic algorithm emphasizes the evaluation with the fragmentation index (DFI).

There is a critical correlation of intrauterine insemination and in vitro fertilization (IVF) with the success rate of pregnancy. There is a new complete explanation about assisted reproduction techniques and some of its characteristics. The guidelines emphasize the role of ultrasound in evaluation, mainly for measuring testicular volume, determining abnormalities in the structure of the testicle (testicular dysgenesis or tumors), and seeing possible indirect signs of obstruction. In infertility-related conditions, the possible role of varicocelectomy in patients with non-obstructive azoospermia, hypogonadism, or patients with altered DNA fragmentation is mentioned as a possible alternative.

There are also invasive treatment options (they refer to the types of sperm retrieval technique and their success rates and surgical techniques for reconstruction of the seminal tract depending on the site of obstruction or compromise). Besides, there are non-invasive techniques (such as changes in lifestyle, hormonal therapy and antioxidants).

Finally, these guidelines, for the first time, reviewed the effects of urological conditions on sexual and reproductive health. There are interesting relationships of varicocele with cardiovascular disease, the psychological effects of prostate cancer on sexual function and the well-known relationship of erectile dysfunction and cardiac conditions. Priapism, male contraception, or vasectomy chapters have no other updates.

In conclusion, the European Guidelines of Urology 2020 are mandatory reading for beginners and experts on the subject. There are novel findings that must be consulted by urologists and residents from all over the world.

\section{References}

1 Aus G, Chapple C, Hanûs T, et al. The European Association of Urology (EAU) guidelines methodology: a critical evaluation. Eur Urol 2009;56(05):859-864. Doi: 10.1016/j.eururo.2008.07.012

2 Salonia A, Eardley I, Giuliano F, et al; European Association of Urology. European Association of Urology guidelines on priapism. Eur Urol 2014;65(02):480-489. Doi: 10.1016/j.eururo.2013.11.008

3 Campbell JD, Trock BJ, Oppenheim AR, Anusionwu I, Gor RA, Burnett AL. Meta-analysis of randomized controlled trials that assess the efficacy of low-intensity shockwave therapy for the treatment of erectile dysfunction. Ther Adv Urol 2019;11:1756287219838364

4 Herati AS, Pastuszak AW. The genetic basis of peyronie's disease: A review. Sex Med Rev 2016;4(01):85-94. Doi: 10.1016/j. sxmr.2015.10.002

5 Lipshultz LI, Goldstein I, Seftel AD, et al. Clinical efficacy of collagenase Clostridium histolyticum in the treatment of Peyronie's disease by subgroup: results from two large, double-blind, randomized, placebo-controlled, phase III studies. BJU Int 2015; 116(04):650-656. Doi: 10.1111/bju.13096

6 Abdel Raheem A, Capece M, Kalejaiye O, et al. Safety and effectiveness of collagenase clostridium histolyticum in the treatment of Peyronie's disease using a new modified shortened protocol. BJU Int 2017;120(05):717-723 